Postgate, J. R. (1951). J. gen. Microbiol. 5, 714-724.

\title{
On the Nutrition of Desulphovibrio desulphuricans
}

\author{
By J. R. POSTGATE \\ Chemical Research Laboratory, Teddington, Middlesex
}

\begin{abstract}
SUMMARY: A liquid medium based on peptone, yeast extract and glucose is described, which is capable of supporting massive growth of Desulphovibrio desulphuricans 'Hildenborough' and certain other strains of sulphate-reducing bacteria. When peptone is used in large amounts yeast extract may be omitted, though yeast extract is stimulatory when the peptone supply is suboptimal. Glucose is better than lactate in this medium. Bicarbonate increases the growth rate. More than one factor is responsible for growth stimulation by peptone and yeast extract; the factors responsible for the stimulation shown by yeast extract in the presence of inadequate peptone are water-soluble and not removed by various extraction procedures. Cysteine promotes growth, and serine, ornithine and isoleucine act synergistically with it. These amino-acids do not account for the whole activity of peptone and yeast extract.
\end{abstract}

The isolation and cultivation of sulphate-reducing bacteria were described by Baars (1930), Starkey (1938), Starkey \& Wight (1945). The liquid media used by these workers were in general based on a carbon source such as lactic acid and inorganic salts, though Stephenson \& Stickland (1931) used a meat broth nutrient agar and Starkey (1938) used a peptone glucose agar for the isolation of discrete colonies. Iya \& Sreenivasaya (1945) showed that urea, peptone or casein hydrolysate stimulated the growth of a halophilic strain. Butlin, Adams \& Thomas (1949) studied the growth of $D$. desulphuricans spp. in some detail and introduced the use of sodium sulphite for the purification of cultures; they also observed that the growth of pure cultures was stimulated by the addition of $0 \cdot 1 \%$ yeast extract. Butlin \& Adams (1947) had previously shown that pure cultures were able to grow autotrophically.

Traditionally, these organisms have been cultivated in the presence of an excess of ferrous iron, their presence being inferred from the black precipitate of ferrous sulphide formed as a result of their metabolism. Butlin et al. (1949) showed that the greater part of this iron was unnecessary, but that, in media freed of iron by 8-hydroxyquinoline, traces were needed. Using reagents which had not been specially purified, together with yeast extract, however, 'rapid and abundant growth' was obtained without added iron and without blackening of the culture. A liquid medium containing peptone, yeast extract, glucose and salts which supported better growth with certain strains than any media previously used has been reported from this laboratory (Postgate, 1949; Report, 1949). Such growth occurred without precipitation of iron sulphide and the medium was used for the preparation of resting-cell suspensions. Miller $(1949 a, b)$ studied the total amounts of hydrogen sulphide produced by sulphate-reducing bacteria in closed vessels, using several different media. The amount of $\mathrm{H}_{2} \mathrm{~S}$ formed was greatly increased by addition 
of peptone, yeast extract, liver extract, potato juice, protein hydrolysates or milk.

Some studies on the factors responsible for the massive growth of $D$. desulphuricans in media based on peptone, yeast extract and glucose are reported here. The growth of the organism has been studied directly, since there is evidence (Postgate, unpublished) that the specific rate of sulphate reduction can vary according to the strain and the age of the culture. Consequently the rate of sulphide production or the precipitation of ferrous sulphide may not be a satisfactory measure of growth. Particular precautions were taken to ensure the purity of the strains used.

\section{METHODS}

Organisms. A strain of Desulphovibrio desulphuricans known as 'Hildenborough', isolated from Wealden clay taken from Hildenborough, Kent, England, in 1946, was the main organism used in this work. It was a typical mesophilic Gram-negative motile vibrio, and was normally grown at $30^{\circ}$. This and all but two of the other strains used were originally purified by cultivation and plating on media containing $3 \% \mathrm{Na}_{2} \mathrm{SO}_{3}$ (Butlin et al., 1949). They were all checked at intervals during the work for aerobic and anaerobic contaminants; none was found.

Media. Stock cultures were maintained on the medium of Baars (1930) and subcultured monthly, but for routine work the organism was subcultured every three or four days in medium A, containing 'Bacto-Peptone' or 'BactoTryptone' (Difco) 5 g.; yeast extract (Difco) 4 g.; $\mathrm{Na}_{2} \mathrm{SO}_{4}, \mathbf{1} \cdot 5$ g.; $\mathrm{MgSO}_{4} \cdot 7 \mathrm{H}_{2} \mathrm{O}$, $1.5 \mathrm{~g}$.; glucose $10 \mathrm{~g}$; ; in 1 l. distilled water, $\mathrm{pH} \mathrm{7.2.} \mathrm{Media} \mathrm{and} \mathrm{solutions}$ of substances to be added were sterilized by autoclaving for $10 \mathrm{~min}$. at $10 \mathrm{lb} . / \mathrm{sq}$. in., except for media containing glucose, which were sterilized by steaming for $1 \mathrm{hr}$. on three successive days. Certain pure substances likely to be unstable to heat were sterilized by Seitz filtration; they are mentioned in the text.

Techniques. Cultures $\left(5 \mathrm{ml}\right.$.) of the organism in 6 in. $\times \frac{3}{4}$ in. soft glass testtubes were incubated in a McIntosh \& Fildes anaerobic jar containing hydrogen and $5 \%(\mathrm{v} / \mathrm{v}) \mathrm{CO}_{2}$, and the palladium catalyst of the jar was protected from $\mathrm{H}_{2} \mathrm{~S}$-poisoning by a cotton-wool pad soaked in lead acetate and dried. For routine subculture $0.5 \mathrm{ml}$. of a grown culture was added to $5 \mathrm{ml}$. of the new culture, but for tests of growth-factor activity a washed inoculum was used. A grown culture (two or three days after inoculation) was centrifuged, resuspended in $0.8 \%$ saline, and its turbidity adjusted to a standard value (100 $\mu \mathrm{g}$. dried cells $/ \mathrm{ml}$.) using a calibrated direct-reading photoelectric colorimeter (The 'E.E.L.', Electroselenium Ltd., Harlow, Essex). This suspension was added to the culture medium to give a final dilution of 1/100. Such a large inoculum was desirable for quantitative work since, though growth occurred with a $1 / 10^{\circ}$ dilution of a grown culture, irregularities in growth rate sometimes occurred with dilutions greater than 1/100.

The extent of growth in a culture was usually judged by inspection, but, 
where necessary, quantitative values were obtained by estimating the turbidity in the 'E.E.L.' colorimeter. Using a blue filter ('E.E.L.' No. 303) which transmitted chiefly light of wavelength $480.0 \mathrm{~m} \mu$., the relationship between turbidity and dry wt. cells/ml. suspension was linear over a satisfactory range. Readings were taken in this range; where necessary the cultures were diluted.

\section{RESULTS}

Optimal $p H$ and the effect of bicarbonate. The organism was not markedly sensitive to the initial $\mathrm{pH}$, and grew well between values of about $6 \cdot 3$ and $8 \cdot 6$. More acid $\mathrm{pH}$ values depressed growth considerably. The rate of growth was more rapid at higher $\mathrm{pH}$ values such as $8 \cdot 6$, though the stationary population was reduced as compared with that obtained at $\mathrm{pH}$ values around 7 .

The $\mathrm{pH}$ of a medium having an initial $\mathrm{pH}$ greater than about 7 tended, over 1-2 hr., to reach this value in an atmosphere of hydrogen $+5 \%(\mathrm{v} / \mathrm{v}) \mathrm{CO}_{2}$, presumably owing to absorption of $\mathrm{CO}_{2}$ as the $\mathrm{HCO}_{3}{ }^{\prime}$ and $\mathrm{CO}_{3}{ }^{\prime \prime}$ ions. Thus the enhanced growth rate shown by $D$. desulphuricans at high initial $\mathrm{pH}$ values could well have been due to a stimulation of growth by free $\mathrm{HCO}_{3}{ }^{\prime}$ ions. This view was tested by setting up a range of cultures of various $\mathrm{pH}$ values greater than $7 \cdot 0$ using known amounts of $\mathrm{NaOH}$, and a comparable range of cultures containing the amount of $\mathrm{NaHCO}_{3}$ which would be formed from the added $\mathrm{NaOH}$ were this hypothesis correct. The addition of $\mathrm{NaHCO}_{3}$ had no significant effect on the initial $\mathrm{pH}$ of the medium, but, nevertheless, caused a stimulation of the growth rate equivalent to that obtained in the cultures containing $\mathrm{NaOH}$. Thus free bicarbonate was preferable to gaseous $\mathrm{CO}_{2}$ for optimal growth of the organism. For routine work, however, it was convenient to avoid the addition of bicarbonate to the cultures, so a $\mathrm{pH}$ value of $7 \cdot 2$ was finally adopted as giving the most satisfactory compromise between a good growth rate and a large stationary population.

The effect of the gas-phase. Medium A had growth-promoting activity in the presence or absence of hydrogen $+\mathrm{CO}_{2}$ though growth was more rapid in its presence. The availability of gas determined the rate of growth of the cultures, since shallow cultures grew faster than deep ones (Fig. 1). It was thus necessary to use vessels of similar dimensions when making quantitative comparisons of bacterial growth.

The effect of peptone. When sufficient peptone was added, yeast extract could be omitted from the medium altogether. Either 'Bacto-Peptone' (Difco) or 'Bacto-Tryptone' (Difco) could be used but certain other proprietary peptones were less active. For optimal growth in the absence of yeast extract $20 \mathrm{mg}$./ml. of peptone were required (Fig. 2).

The effect of yeast extract. Yeast extract did not replace peptone satisfactorily since it depressed growth at high concentrations (Fig. 2). Growth with all concentrations of yeast extract appeared slower than with similar amounts of peptone but this effect was not studied in detail. With partially inhibitory concentrations of yeast extract the medium became darkened during growth, and allowance was made for this in obtaining the readings for Fig. 2. 
The effect of peptone and yeast extract. A mixture of peptone and yeast extract exerted a greater growth-stimulating effect than either substance exerted separately, and was consequently preferable for routine subculture of the organism. Optimal growth was obtained using $5 \mathrm{mg} . / \mathrm{ml}$. peptone and $4 \mathrm{mg} . / \mathrm{ml}$. yeast extract (Fig. 3). The greater specific activity of a mixture

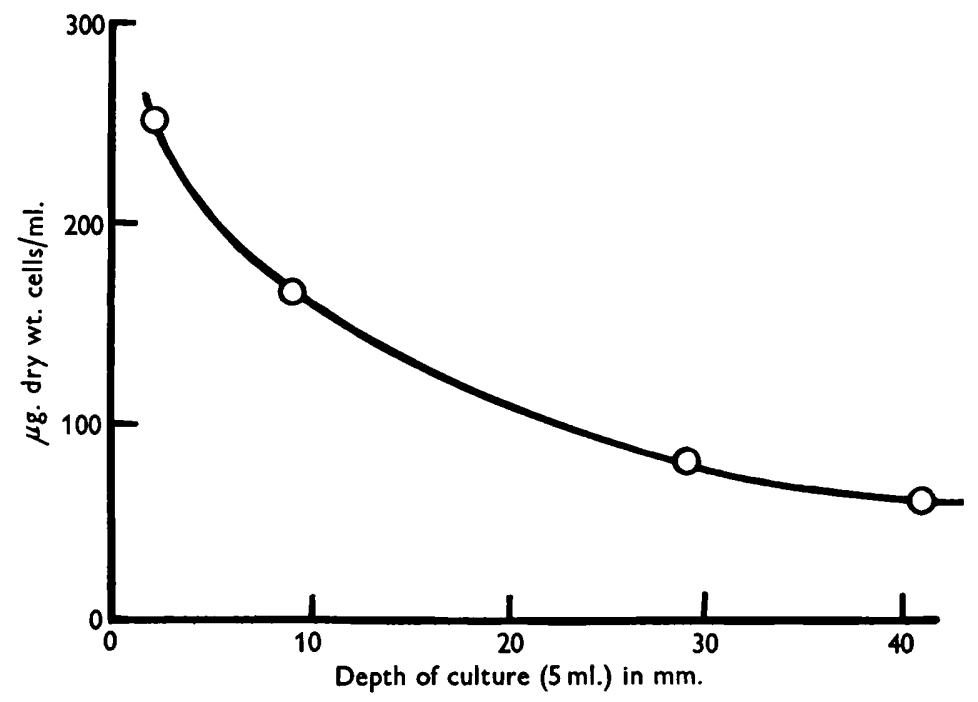

Fig. 1. Growth of $D$. desulphuricans 'Hildenborough' after $48 \mathrm{hr}$. in $5 \mathrm{ml}$. cultures of various depths.

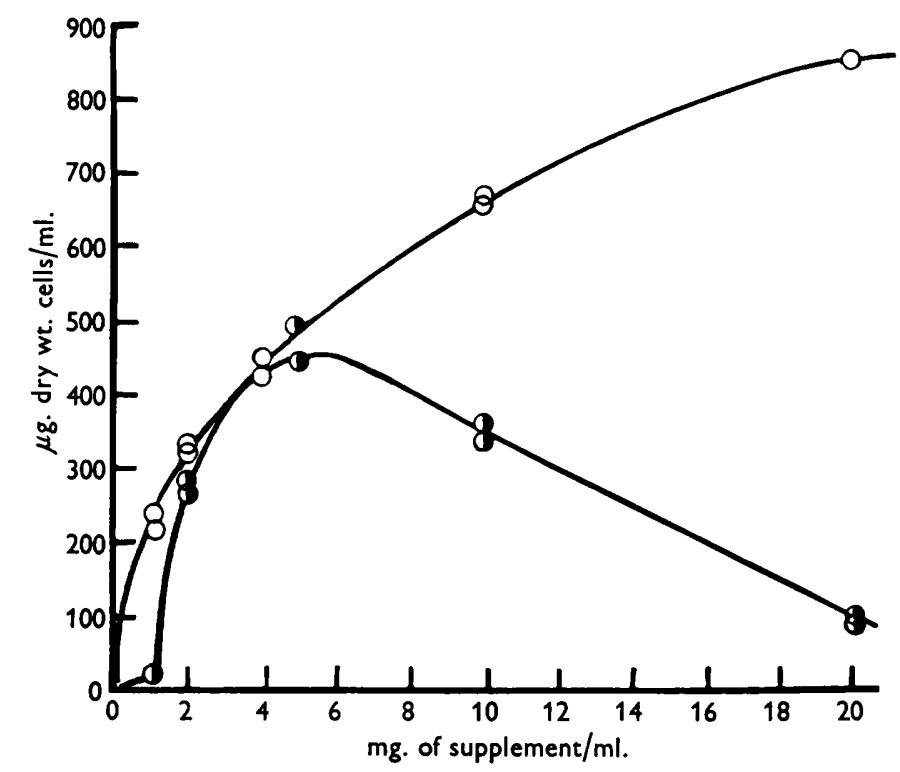

Fig. 2. Growth of $D$. desulphuricans 'Hildenborough' in a medium of glucose, salts and various supplements. $O$ growth after $72 \mathrm{hr}$. with 'Bacto-Tryptone'; $O$ growth after $94 \mathrm{hr}$. with 'Difco' yeast extract. 
of peptone and yeast extract compared with that of either used alone suggested that several factors were responsible for their stimulatory effect, some being more plentiful in yeast extract and others more plentiful in peptone.

The effect of other supplements. Casein hydrolysate (Ashe Laboratories, vitamin-free) was active in place of peptone and yeast extract, but growth with $20 \mathrm{mg} . / \mathrm{ml}$. of this material was markedly inferior to growth with $20 \mathrm{mg} . / \mathrm{ml}$. 'Bacto-Peptone' (Difco). Partial enzymatic digests of casein

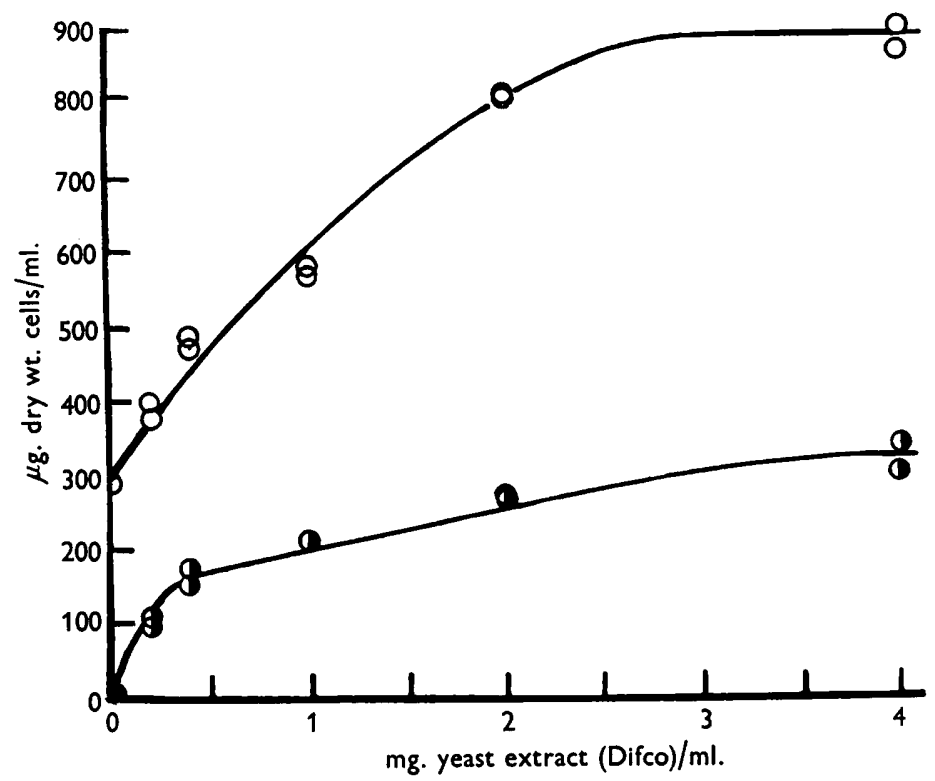

Fig. 3. Effect of yeast extract on the growth of $D$. desulphuricans 'Hildenborough' after $70 \mathrm{hr}$. O growth with 'Bacto-Peptone' (5 g./l.), glucose (10 g./l.) and salts; 1 growth with lactic acid and salts (Starkey, 1938).

obtained by using trypsin were also active, and so were partial hydrolysates of casein prepared by using sulphuric acid.

An extract prepared by boiling garden soil with an equal volume of water for $30 \mathrm{~min}$. had no growth-promoting action, and an extract of fully-grown cells of $D$. desulphuricans prepared by boiling for $30 \mathrm{~min}$. and centrifuging was also inactive.

Some studies with Starkey's medium. Growth in a medium consisting of lactic acid and salts (Starkey, 1938) was shown to be stimulated by $1 \mathrm{mg} . / \mathrm{ml}$. yeast extract (Butlin et al., 1949). Fig. 3 shows that greater quantities of yeast extract stimulated growth further, but not to the level obtained with glucose and peptone.

Glucose was an important constituent of the new medium since cultures in Starkey's medium enriched with $0.1 \%(\mathrm{w} / \mathrm{v})$ 'Bacto-Tryptone' $+\mathbf{0} \cdot \mathbf{2} \%(\mathrm{w} / \mathrm{v})$ yeast extract gave only $420 \mu \mathrm{g}$. dry wt. of cells $/ \mathrm{ml}$. after $72 \mathrm{hr}$. incubation, as compared with $710 \mu \mathrm{g}$. dry wt. of cells $/ \mathrm{ml}$. obtained in parallel cultures with the same supplements+glucose $(1 \% \mathrm{w} / \mathrm{v})$ and salts. In both media the 
carbon sources were present in excess of the normal requirement of the organism.

Some tests with other strains of $\mathrm{D}$. desulphuricans. Massive growth in medium A was not shown by all strains of sulphate-reducing bacteria, though growth was usually superior to that obtained in lactic acid +yeast extract media. A test using strains usually subcultured at $30^{\circ}$ is recorded in Table 1 , where the growth in medium A was compared with the growth in Starkey's lactic acid medium with $0 \cdot 1 \%(\mathrm{w} / \mathrm{v})$ yeast extract added as used by Butlin et al..(1949). The inoculum for this test was prepared from a culture grown in medium A, so if an adaptive process were involved in the response to these media the differences shown in Table 1 are exaggerated in favour of medium A. The results, nevertheless, distinguish between those strains which give a considerable response to the new medium and those which do not.

\section{Table 1. Growth of D. desulphuricans in various media}

\begin{tabular}{|c|c|c|c|}
\hline Strain & $\begin{array}{l}\mu \mathrm{g} . \text { of dried cells } / \mathrm{ml} . \\
\text { in peptone-yeast- } \\
\text { glucose medium }\end{array}$ & $\begin{array}{c}\mu \mathrm{g} . \text { of dried cells } / \mathrm{ml} \text {. } \\
\text { in lactate-yeast-salts } \\
\text { medium }\end{array}$ & $\begin{array}{l}\text { Hours of } \\
\text { Incubation }\end{array}$ \\
\hline Wandle & 500 & 70 & 120 \\
\hline Teddington $\mathbf{M}$ & 190 & 60 & 120 \\
\hline Teddington $\mathbf{R}$ & 360 & 135 & 120 \\
\hline *Texas 29.12.B & 400 & 190 & 96 \\
\hline Essex 6 & 425 & 115 & 120 \\
\hline Hildenborough & 500 & 120 & 120 \\
\hline *New Jersey, Sol C-1 & 240 & 180 & 96 \\
\hline *Holland, D-6 & 210 & 150 & 96 \\
\hline *Holland, SH-1 & 230 & 170 & 96 \\
\hline
\end{tabular}

An inconsistency has been noted in the behaviour of some strains. On the first occasion of testing 'Essex 6' showed little stimulation of growth in the new medium, though some months later (after a few subcultures in Baars's medium) the effect recorded in Table $\mathbf{1}$ was observed. Similarly 'Teddington $\mathbf{R}^{\prime}$ ' (a strain distinguished from all others yet isolated by being non-motile), when first tested showed as remarkable an effect as 'Hildenborough', though after a few passages on Baars's medium the effect had diminished. The strain was morphologically unchanged. On yet another occasion 'Hildenborough' lost its ability to grow profusely in medium $\mathbf{A}$, though it had been subcultured for 90 passages in this medium, regularly giving massive growth. A new series from the stock culture in Baars's medium behaved satisfactorily. The reason for these irregularities is unknown; in the last-mentioned case the alteration was not due to any change in the batch of medium, the brand or batch of peptone, yeast extract or glucose, or to the atmosphere, the $\mathrm{pH}$ of the medium or the inoculum size. The culture was uncontaminated and morphologically unaltered.

Some chemical tests on yeast extract. Though there were probably several factors responsible for the stimulation of growth obtained with peptone and 
yeast extract, it was nevertheless likely that all of these were present in peptone, as large amounts of peptone would support optimal growth in the absence of yeast extract. With insufficient peptone it was likely that yeast extract in stimulating growth was acting by means of a factor or factors not plentiful in peptone. Since in these conditions the number of factors experimentally sought was decreased, tests on the chemical behaviour of yeast extract (Difco) were undertaken using medium $\mathbf{A}$ without yeast extract as a test medium. The following points were established:

(1) The factors in yeast extract were stable to heat. The material could be sterilized in steam for $10 \mathrm{~min}$. at $10 \mathrm{lb}$. $/ \mathrm{sq}$. in. and when this was increased to $20 \mathrm{~min}$. at $20 \mathrm{lb}$. $/ \mathrm{sq}$. in. there was no loss of activity.

(2) A distillate from the pyrolysis of dry yeast extract was inactive.

(3) Activity remained exclusively in the residue after extraction of yeast extract with chloroform, benzene, $60-80^{\circ}$ ligroin, acetone and ethanol.

(4) Activity remained exclusively in the aqueous phase after continuous extraction of aqueous solutions at $\mathrm{pH} \mathrm{3,6,9}$ and 12 with diethyl ether.

(5) Aqueous solutions treated with excess of acetone or ethanol gave a precipitate which contained the active factors.

(6) Neither animal charcoal nor 'Brockman' alumina removed the active factors from a neutral aqueous solution.

Similar tests were not in general carried out with peptone owing to the complex nature of its activity. Peptone, however, remained active after autoclaving for $10 \mathrm{~min}$. at $10 \mathrm{lb} . / \mathrm{sq}$. in., and its activity was lost on ashing. This last test indicated that the activity of peptone was not due to the presence of non-volatile inorganic constituents.

Some tests of substances having biological activity. A number of pure biologically-active substances was tested for ability to replace peptone and yeast extract in a medium containing glucose (10 g.), $\mathrm{Na}_{2} \mathrm{SO}_{4}(1.5 \mathrm{~g}$.), and $\mathrm{MgSO}_{4} \cdot 7 \mathrm{H}_{2} \mathrm{O}(1.5 \mathrm{~g}$ ), in $1 \mathrm{l}$. Since there was a deficiency of phosphate and inorganic nitrogen, which might have led to a failure to detect activity with a pure substance, 1 g. $\mathrm{NH}_{4} \cdot \mathrm{H}_{2} \mathrm{PO}_{4} / \mathrm{l}$. was added. It was desirable to sterilize the phosphate separately as in its presence some caramelization of the medium occurred during steam sterilization. A washed inoculum of D. desulphuricans 'Hildenborough' was used for all tests. The test substances, except for those mentioned, were sterilized by autoclaving for $10 \mathrm{~min}$. at $10 \mathrm{lb} . / \mathrm{sq}$. in.

The compounds were tested singly, in groups, and finally as a mixture. After four or five days limited growth usually occurred in the basal medium, and where this growth was inhibited the compound was retested. This phenomenon occurred once only, when 2-methyl-1 : 4-naphthaquinone depressed growth slightly at $10 \mu \mathrm{g} . / \mathrm{ml}$. The compounds and the highest concentrations tested are listed in Table 2.

Most of these compounds are of well-known biological importance, but some may require explanation. Carotene and $\beta$-indoleacetic acid are not known to be important in the metabolism of micro-organisms : a report that the latter 
Table 2. Substances tested as growth factors for D. desulphuricans 'Hildenborough', and the highest test concentrations used

Vitamins
$p$-Aminobenzoic acid
Aneurin
Ascorbic acid
B $_{12 *}$
Biotin**
Carotene
Choline*
Haemin
m-Inositol
Nicotinic acid
Nicotinamide
Oleic acid
Pantothenic acid
Pteroylglutamic acid
Pyridoxine*
Pyridoxal*
Pyridoxamine*
Riboflavine*
Miscellaneous
Ammonium acetate
Asparagine
Glutamine*
Glutathione*
$\beta$-Indoleacetic acid
2-methyl-1 : 4-
naphthaquinone
Putrescine
'Reductone'*
Sodium bicarbonate
'Tween 80'
Urea*

$100 \mathrm{~m} \mu \mathrm{g} \cdot / \mathrm{ml}$.
$100 \mu \mathrm{g} . / \mathrm{ml}$.
$100 \mu \mathrm{g} \cdot / \mathrm{ml}$.
$4 \mathrm{~m} \mu \mathrm{g} \cdot / \mathrm{ml}$.
$100 \mathrm{~m} \mu \mathrm{g} \cdot / \mathrm{ml}$.
saturated
$100 \mu \mathrm{g} . / \mathrm{ml}$.
saturated
$100 \mu \mathrm{g} \cdot / \mathrm{ml}$.
$100 \mu \mathrm{g} . / \mathrm{ml}$.
$100 \mu \mathrm{g} . / \mathrm{ml}$.
saturated
$100 \mu \mathrm{g} . / \mathrm{ml}$.
$100 \mathrm{~m} \mu \mathrm{g} . / \mathrm{ml}$.
$100 \mu \mathrm{g} . / \mathrm{ml}$.
$100 \mu \mathrm{g} . / \mathrm{ml}$.
$100 \mu \mathrm{g} . / \mathrm{ml}$.
$100 \mu \mathrm{g} . / \mathrm{ml}$.

$1 \mathrm{mg} \cdot / \mathrm{ml}$.

$1 \mathrm{mg} . / \mathrm{ml}$.

$1 \mathrm{mg} \cdot / \mathrm{ml}$.

$1 \mathrm{mg} . / \mathrm{ml}$.

$10 \mu \mathrm{g} . / \mathrm{ml}$.

$1 \mu \mathrm{g} . / \mathrm{ml}$.

$5 \mu \mathrm{g} . / \mathrm{ml}$.

$1 \mathrm{mg} . / \mathrm{ml}$.

$5 \mathrm{mg} \cdot / \mathrm{ml}$.

$100 \mu \mathrm{g} . / \mathrm{ml}$.

$10 \mathrm{mg} . / \mathrm{ml}$.

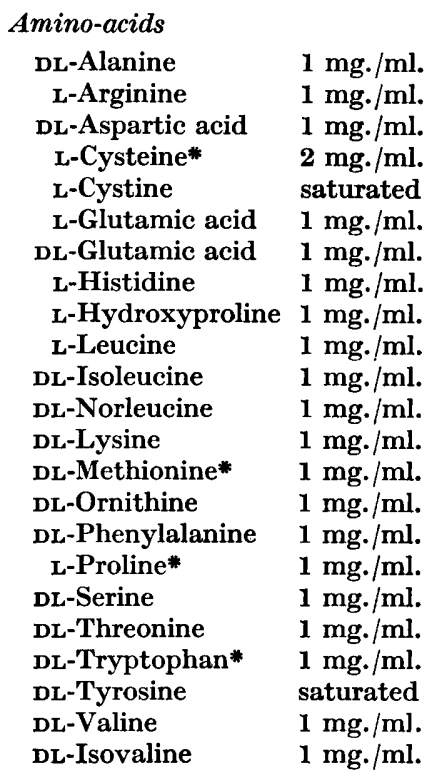

Purines, etc.

Adenine $\quad 1 \mathrm{mg} \cdot / \mathrm{ml}$.

Allantoin $\quad 1 \mathrm{mg} . / \mathrm{ml}$.

Guanine saturated

Thymine $1 \mathrm{mg} . / \mathrm{ml}$.

Uracil $1 \mathrm{mg} . / \mathrm{ml}$.

Xanthine saturated

* Sterilized by Seitz-filtration.

*** Obtained sterile.

promoted the growth of Escherichia coli bacteriophage (Cohen \& Fowler, $1947 a$ ) has been withdrawn (Cohen $\&$ Fowler, 1947 $b$ ). It was, nevertheless, thought desirable to test them since they were available. 2-Methyl-1: 4-naphthaquinone has vitamin $K$ activity for certain organisms (Knight, 1945) and was used in place of phthiocol which was not available. 'Reductone' (CHO . $\mathrm{C}(\mathrm{OH}): \mathrm{CHOH})$ is a compound which may be important in the biosynthesis of the pterin group of factors (Forrest \& Walker, 1948) and, since it is also formed by the partial oxidation of glucose (O'Meara, McNally \& Nelson, 1944, 1947), any activity found could account for the importance of glucose in the medium. Ammonium acetate was tested since acetate has been shown to be important for the growth of certain organisms (e.g. Collins, Nelson \& Parmelee, 1950) and also to ensure that the basal medium was not merely deficient in nitrogen as $\mathrm{NH}_{4}+$. Sodium bicarbonate was tested since it has already been shown to increase the growth rate in rich media, and ascorbic 
acid, though not a growth factor for bacteria, was tested because its powerful reducing properties might assist the growth of an anaerobe. Urea was tested for two reasons: firstly, Iya \& Sreenivasaya (1945) showed that it accelerated sulphide formation by a halophilic strain of $D$. desulphuricans, and secondly, it is biologically related to ornithine through the cycle proposed by Krebs for the formation of urea in tissues. Ornithine was one of the materials found to be active.

In view of the inactivity of peptone ash it was unlikely that the activity of peptone was due to its supplying traces of inorganic materials to the organism unless these were volatile. To confirm this view tests were carried out on a solution containing the following elements such that the concentration of each constituent was between 1 and $10 \mu \mathrm{g} . / \mathrm{ml} .: \mathrm{Fe}^{++}, \mathrm{Fe}^{+++}, \mathrm{Al}^{++}, \mathrm{Cu}^{++}, \mathrm{Mg}^{++}$, $\mathrm{UO}_{2}{ }^{++}, \mathrm{Zn}^{++}, \mathrm{Mn}{ }^{++}, \mathrm{As}, \mathrm{Si}, \mathrm{B}, \mathrm{Mo}$ and $\mathrm{V}$ (the last five as oxy-acid anions). This mixture was inactive both alone and with a suboptimal amount of peptone $(5 \%, \mathrm{w} / \mathrm{v})$.

Of the materials listed in Table 2 only cysteine was active in the first series of tests, and an optimal concentration of $2 \mathrm{mg}$. $/ \mathrm{ml}$. was established. The tests were repeated in the presence of this material, and serine, ornithine and isoleucine were found to have synergistic activity with cysteine. A mixture of these four amino-acids (cysteine $2 \mathrm{mg}$. $/ \mathrm{ml}$., serine $1 \mathrm{mg} . / \mathrm{ml}$., ornithine $1 \mathrm{mg} . / \mathrm{ml}$. and isoleucine $1 \mathrm{mg}$. $/ \mathrm{ml}$.) was able to support growth up to $1 / 5$ of that obtained with optimal amounts of peptone. This is indicated in Table 3.

Table 3. Growth of D. desulphuricans after $96 \mathrm{hr}$. with various amino-acids

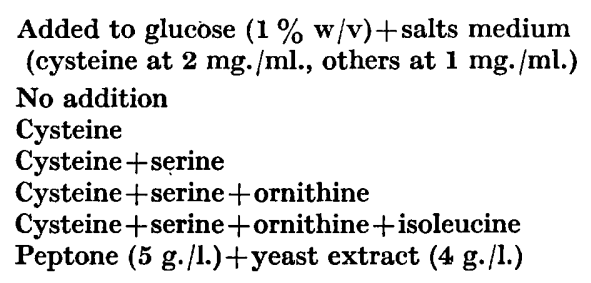

These amino-acids were also active towards $D$. desulphuricans strain 'Essex 6', though at the time of testing this strain did not show the remarkable stimulation of growth in peptone yeast extract glucose medium found with 'Hildenborough' (or with 'Essex 6' at a later date-see above) (Table 3).

With 'Hildenborough' strain, growth with the four amino-acids at the concentrations mentioned was not improved by the following expedients:

(1) Doubling the amino-acid concentration.

(2) Doubling the concentration of each active amino-acid in turn.

(3) Decreasing the concentration of each amino-acid in turn to $40 \%$ of the values mentioned. 
(4) Adding all the compounds listed in Table 2 (excluding ammonium acetate, urea, and sodium bicarbonate) either separately or as a mixture.

(5) Adding yeast extract at a concentration ( $1 \mathrm{~g}$. $/ 1$.) active when the aminoacids are replaced by a suboptimal amount ( $5 \mathrm{~g}$./1.) of peptone.

It was, therefore, likely that substances other than those tested were present in peptone and yeast extract and were mainly responsible for their activity; the four active amino-acids might be present and might contribute to the activity.

\section{DISCUSSION}

Of the amino-acids cysteine, ornithine, serine and isoleucine, which stimulated growth, cysteine was the most important, since the other amino-acids were not active in its absence. It is probable that ornithine, serine and isoleucine were acting in their own right rather than through an impurity of biological activity since they were of synthetic origin. No specimen of synthetic cysteine was available for testing, so the possibility remains that its activity was due to impurity.

These four amino-acids may be present in peptone and may contribute to its activity, but the evidence was against their being responsible for the whole of its activity. They supported considerably less growth than peptone, and this limited growth was not due to antagonisms among the active aminoacids, since alteration of their ratios effected no improvement. On the other hand, they were the racemic mixtures of the amino-acids: the laevo-isomers, had they been available, might have shown greater activity. However, the fact that they were active for a strain of $D$. desulphuricans which showed little stimulation by peptone suggests that they were not responsible for the greater stimulation which occurred with the test strain. It is, therefore, likely that at least one other factor was responsible for the activity of peptone.

It is possible that the missing factor or factors were of the polypeptide group, since peptone is likely to be rich in such compounds, as were the partial tryptic digests of casein which were also active. Sprince \& Woolley (1945) have shown that a substance of this nature, strepogenin, is required for the growth of certain lactic bacteria. No preparation of strepogenin was available for testing, but the partial tryptic casein digests were prepared so as to conserve this material as much as possible (Dr Woolley, personal communication). Smith \& Douglas (1950) have also reported an unidentified factor necessary for the growth of Clostridium bifermentans, which they believe to be a peptide other than strepogenin. This is present in peptone preparations and partial digests and hydrolysates of proteins, and its solubility properties resemble those of the yeast-extract component studied here.

Rittenberg (1941) found that peptone lactate agar was as effective as peptone glucose agar for the growth of marine sulphate-reducing bacteria, but in the present studies glucose was necessary for the full growth-promoting effect of medium A. The reason for this is not known, though formation of reductone was shown to play no part in the effect. 
The author is indebted to Dr W. W. Umbreit for a gift of pyridoxamine, to Dr E. F. Gale for gifts of pyridoxal and $m$-inositol, to $\mathrm{Dr} D$. D. Woods for gifts of pteroylglutamic acid and 'Tween 80', to Dr I. Jones for a gift of 2-methyl-1 : 4-naphthaquinone, to Dr S. Thomas for a gift of $1: 4$-tetramethylenediamine, to Dr J. Walker for a gift of reductone and Dr W. Cuthbertson for supplies of vitamin $B_{12}$.

He is also indebted to Miss M. G. French for assistance in the studies concerned with $\mathrm{pH}$ and to $\mathrm{Mr}$ K. R. Butlin for his interest and advice. This paper is published by permission of the Director, Chemical Research Laboratory.

\section{REFERENCES}

BaARs, J. K. (1930). Over Sulphatreductie door Bacterien. Dissertation, W. D. Meinema, N.V., Delft, Holland.

Butlin, K. R. \& Adams, M. E. (1947). Autotrophic growth of sulphate-reducing bacteria. Nature, Lond., 160, 154.

Butlin, K. R., Adams, M. E. \& Thomas, M. (1949). The isolation and cultivation of sulphate-reducing bacteria. J. gen. Microbiol. 3, 46.

Cohen, S. S. \& Fowler, C. B. (1947 a). The stimulation of bacteriophage synthesis by indole-3-acetic acid. J. biol. Chem. 167, 625 .

Cohen, S. S. \& Fowler, C. B. $(1947 b)$. On the reported stimulation of bacteriophage synthesis by indole-3-acetic acid. J. biol. Chem. 168, 775 .

Collins, E. B., Nelson, F. E. \& Parmelee, C. E. (1950). Acetate and oleate requirements of the lactic group of streptococci. J. Bact. 59,69 .

Forrest, H. S. \& Walker, J. (1948). Reductone and the synthesis of pteridines. Nature, Lond., 161, 721.

IyA, K. K. \& Sreenivasaya, M. (1945). Studies in the sulphur formation at Kona, Masulipatam. Curr. Sci. No. 10, 267.

KNIGHT, B. C. J. G. (1945). Growth factors in microbiology. Vitamins and Hormones, 3, 105. New York: Acadamic Press Inc.

Milier, L. P. (1949a). Rapid formation of high concentrations of hydrogen sulphide by sulphate-reducing bacteria. Contr. Boyce-Thompson Inst. 15, 437.

Miller, L. P. (1949b). Stimulation of hydrogen sulphide production by sulphatereducing bacteria. Contr. Boyce-Thompson Inst. 15, 467.

O'Meara, R. A., McNally, P. A. \& Nelson, H. G. (1944). Bacteriostatic action of sulphonamide derivatives. Nature, Lond., 154, 796.

O'Meara, R. A., McNally, P. A. \& Nelson, H. G. (1947). The intracellular mode of action of sulphonamide derivatives. Lancet, ii, 747 .

Postgate, J. R. (1949). Competitive inhibition of sulphate reduction by selenate. Nature, Lond., 164, 670.

Report (1949). Chemistry Research 1948. H.M. Stationery Office, London.

RitTenberg, S. C. (1941). Studies on marine sulphate-reducing bacteria. Thesis, Univ. of California.

Smith, L. D. \& Douglas, H. C. (1950). Factors necessary for maximum growth of Clostridium bifermentans. J. Bact. 60, 9.

Sprince, H. \& Woolley, D. W. (1945). The occurrence of the growth factor strepogenin in purified proteins. J. Amer. chem. Soc. 67, 1734.

Starkey, R. L. (1938). A study of spore formation and other morphological characteristics of Vibrio desulphuricans. Arch. Mikrobiol. 9, 268.

Starkey, R. L. \& Wight, K. M. (1945). Anaerobic corrosion of Iron in Soil: Final report of the American Gas Assocn. Iron Corrosion Res. Fellowship, Amer. Gas. Ass. N.Y.

Stephenson, M. \& Stickland, L. (1931). The reduction of sulphate to sulphide by molecular hydrogen. Biochem. J. 25, 215.

(Received 9 October 1950) 